\title{
Polyamine Content Changes in Creeping Bentgrass Exposed to Salt Stress
}

\author{
Yingmei Ma and Emily Merewitz ${ }^{1}$ \\ Department of Plant, Soil, and Microbial Sciences, Michigan State University, 1066 Bogue Street, \\ East Lansing, MI 48824
}

\begin{abstract}
AdDitional INDEX wORDs. putrescine, spermidine, spermine
Abstract. Salt stress is a major problem in turfgrass management. Investigation of metabolites, such as polyamines (PAs) that may improve salt tolerance of turfgrass species, is needed. Two independent growth chamber studies were conducted to evaluate physiological characteristics and changes in PAs, such as putrescine (Put), spermidine (Spd), and spermine (Spm), in response to salt stress in 'Penncross' and 'PsgSLTZ' creeping bentgrass (Agrostis stolonifera). The study also aimed to determine a method of PA extraction to improve PA yields from creeping bentgrass. Salt solutions were drench applied to plants growing in pure sand daily in a stepwise manner for $\approx 70$ days in both studies. For both cultivars, salt stress caused an increase in leaf $\mathrm{Na}^{+}$content, percent of electrolyte leakage (EL), and canopy temperature depression (CTD) while it caused a decrease in turf quality (TQ), osmotic potential ( $\Psi_{\mathrm{s}}$ ), and $\mathrm{K}^{+}$and $\mathrm{Ca}^{2+}$ content compared with controls. In the early stages of salt stress, Put content increased in salt-stressed plants compared with controls. Spd content did not change significantly while a transient increase in Spm was observed in the later stage of salt stress. The PA quantification method used in this study included using formic acid during the extraction process, which exhibited enhanced quantification of PAs from creeping bentgrass compared with other methods previously published. Salinity stress upregulated the content of Put and Spm in leaf tissue, which may be involved in salinity tolerance in creeping bentgrass, while Spd accumulation may not be a major salt tolerance mechanism; supplementation with these biochemical compounds could be an alternative to improve creeping bentgrass salt tolerance.
\end{abstract}

Salt stress is a major issue for turfgrass management around the world. Use of reclaimed, nonpotable water that may contain high levels of salts is becoming a common management practice (Duncan et al., 2008). Additionally, numerous turf areas are located in salt-prone environments, such as shorelines or areas with salt-afflicted soils. The primary damage to plants caused by salinity is due to toxic ion accumulation of $\mathrm{Na}^{+}$in plant tissues and water deprivation from decreased external $\Psi_{\mathrm{s}}$ in the soil solution (Hasegawa et al., 2000). Creeping bentgrass does not possess major salt resistance mechanisms to rid plants of salt, such as salt glands, that are found in other grass species within Poaeceae (Marcum, 2001). Since adequate avoidance mechanisms are not possessed by creeping bentgrass, the species must rely on other salt tolerance mechanisms for survival under salt stress conditions. Evaluating mechanisms that may promote tolerance to salt stress is necessary to develop salt-tolerant creeping bentgrass germplasm. Cultivar variation in salt tolerance of creeping bentgrass does exist, but the major metabolite pathways that may play a role in differential salt tolerance mechanisms between cultivars have not yet been fully elucidated. Additionally, knowledge of plant metabolites important in salt stress tolerance could lead to the development of new plant-protective chemical products.

A relatively unexplored biochemical process in turfgrass species is the PA biosynthetic pathway. The common PAs

Received for publication 1 June 2016. Accepted for publication 14 July 2016. We thank AgBioResearch of Michigan State University, Project GREEEN, and The Michigan Turfgrass Foundation for funding support of this work. We also thank Arthur Danial Jones and Lijun Chen of Michigan State University Mass Spectrometry and Metabolomics Core for technical assistance and immense help with method modification of PA quantification.

${ }^{1}$ Corresponding author. E-mail: merewitz@msu.edu. associated with growth regulation and abiotic stresses are Put, $\mathrm{Spd}$, and Spm. PAs are synthesized from arginine or ornithine decarboxylation pathways (Janowitz et al., 2003). PAs may respond differently to abiotic stress based on plant species, plant tissue type, and developmental stage (Capell et al., 2004). In arabidopsis (Arabidopsis thaliana), there was a shift in PA biosynthesis pathways toward accumulating Put, whereas in the resurrection plant (Craterostigma plantagineum) this shift was toward accumulating Spm (Alcazar et al., 2011). Conversely, after salt stress in broad bean [Vicia faba (Sadak and Abdelhamid, 2015)] and foxtail millet [Setaria italica (Sudhakar et al., 2015)], all three types of endogenous PA concentration increased significantly compared with the control. In a salt-tolerant rice (Oryza sativa) cultivar, Put and Spm increased more compared with the sensitive one (Do et al., 2014). In maize (Zea mays) leaf blade elongation zone (Rodriguez et al., 2009), an increase of Spd content was observed in response to salt treatment. Recently, Li et al. (2015a) found that PAs were generally upregulated in white clover (Trifolium repens) under artificially induced drought stress in hydroponic cultures. In creeping bentgrass, Spd content decreased due to drought stress, whereas Put and Spm content increased compared with control plants (Li et al., 2015b). All these results show the importance of PA in salt stress responses. However, it is not yet fully clear whether differences in PA fluctuation during stress is due to species differences, plant developmental stage, or difficulties in comparing across studies.

Compared with other crop species, little information is available regarding the function, content, or regulation of PAs in creeping bentgrass or other cool-season turfgrass species, particularly during long-term salt stress conditions. For utility as an agricultural technology, determining how the common PAs, such as Put, Spd, and Spm, may respond to stress or play 
a role in turfgrass tolerance to stress deserves investigation. In addition, current PA quantification methods used in other crop species and turfgrasses did not prove to provide adequate recovery of free PAs from creeping bentgrass tissue in our preliminary tests. Therefore, the objectives of the study were to improve the methods of extraction and quantification of PAs from creeping bentgrass tissues, evaluate creeping bentgrass physiological health under salt stress, and quantify PAs from creeping bentgrass to achieve a better understanding of PA content regulation due to prolonged salt stress conditions.

\section{Materials and Methods}

Plant preparation and stress treatment. Two independent growth chamber studies (Expts. 1 and 2) were conducted. For both experiments, creeping bentgrass 'PsgSLTZ' and 'Penncross' were used. Seeds of both cultivars were obtained from the Seed Research of Oregon (Tangent, OR). These cultivars showed good performance under salt conditions in their breeding efforts; however, PsgSLTZ rated higher in salt tolerance (Seed Research of Oregon, unpublished data). Seeds were directly sown into pots $\left(12 \mathrm{~cm}^{2}\right)$ at a rate of $4.88 \mathrm{~g} \cdot \mathrm{m}^{-2}$ into pure sand. Expt. 1 was seeded on 18 Aug. 2013 and Expt. 2 on 14 Mar. 2014. The seedlings for both experiments were established in the greenhouse under $900 \mu \mathrm{mol} \cdot \mathrm{m}^{-2} \cdot \mathrm{s}^{-1}$ of photosynthetically active radiation $(P A R)$ for $14 \mathrm{~h}$ of daylength under $65 \%$ to $75 \%$ humidity and $24 / 18{ }^{\circ} \mathrm{C}$ (day/night) temperature for $\approx 2$ months to attain dense and healthy turf canopy. Then, the fully established plants were transferred to an environmentally controlled growth chamber with $700 \mu \mathrm{mol} \cdot \mathrm{m}^{-2} \cdot \mathrm{s}^{-1} P A R$ for $14 \mathrm{~h}$ of daylength, $65 \%$ to $70 \%$ humidity, and $23 / 18{ }^{\circ} \mathrm{C}$ (day/ night) temperatures for both experiments.

Treatments were arranged in a randomized complete block design with four biological replications. All salt-treated plants were watered daily each week with $100 \mathrm{~mL}$ of salt solution at 0 (21 Dec. 2013), 12 (7 d), 12 (21 d), 16 (35 d), 16 (42 d), 20 $(56 \mathrm{~d})$, and $24(70 \mathrm{~d}) \mathrm{dS} \cdot \mathrm{m}^{-1}$ for Expt. 1. The salt solution (Instant Ocean Aquarium Salt; Spectrum Brands, Blacksburg, VA) was made with half strength Hoagland solution (Hoagland and Arnon, 1950) twice per week. The salt solution was made from deionized water the rest of the $5 \mathrm{~d}$ within the week. The salt solution included $10.78 \mathrm{~g} \cdot \mathrm{L}^{-1} \mathrm{Na}^{+}, 0.42 \mathrm{~g} \cdot \mathrm{L}^{-1} \mathrm{~K}^{+}, 1.32 \mathrm{~g} \cdot \mathrm{L}^{-1}$ $\mathrm{Mg}^{2+}, 0.4 \mathrm{~g} \cdot \mathrm{L}^{-1} \mathrm{Ca}^{2+}, 0.008 \mathrm{~g} \cdot \mathrm{L}^{-1} \mathrm{Sr}^{2+}, 19.29 \mathrm{~g} \cdot \mathrm{L}^{-1} \mathrm{Cl}^{-}, 2.66$ $\mathrm{g} \cdot \mathrm{L}^{-1} \mathrm{SO}_{4}{ }^{2-}, 0.2 \mathrm{~g} \cdot \mathrm{L}^{-1} \mathrm{HCO}_{3}{ }^{-}, 0.56 \mathrm{~g} \cdot \mathrm{L}^{-1} \mathrm{Br}^{-}$, and $0.001 \mathrm{~g} \cdot \mathrm{L}^{-1} \mathrm{~F}^{-}$. The percentage of $\mathrm{NaCl}$ in the salt solution was $84 \%$. The same amounts of salt solution were used in Expt. 2, which were applied at 0 (6 May 2014), 4 (28 d), 8 (35 d), 12 (49 d), 16 $(63 \mathrm{~d})$, and $20(77 \mathrm{~d}) \mathrm{dS} \cdot \mathrm{m}^{-1}$.

Physiological trait evaluation. TQ ratings were based on color, density, and uniformity of the grass canopy using a scale of 1-9 with 1 being dead plants and 9 being healthy and green plants (Beard, 2001). Percent EL was measured to estimate cell membrane stability of the leaves based on the method of Blum and Ebercon (1981). About 10 leaves were cut, briefly washed, and immersed in a $15-\mathrm{mL}$ centrifuge tube with $7.5 \mathrm{~mL}$ of deionized water. They were then placed on a shaker for $24 \mathrm{~h}$ at $144 \mathrm{rpm}$. The conductivity of the solution containing the living tissue was measured using an electric conductivity meter (3200 conductivity meter; YSI, Yellow Springs, $\mathrm{OH}$ ) as the initial conductivity $\left(C_{\mathrm{i}}\right)$ after shaking. The leaf tissues were boiled in a water bath for $5 \mathrm{~h}$ and then were placed on a shaker with the same speed for another $24 \mathrm{~h}$. The electric conductivity of the solution containing dead tissues was measured as the maximum conductivity $\left(C_{\max }\right)$. The percent EL was calculated as $C_{\mathrm{i}} / C_{\max } \times 100$.

The $\Psi_{\mathrm{s}}$ was determined as in the method of Qian and Fry (1997). About 10 leaves were taken from each plant and were immersed in deionized water in a petri dish for $3 \mathrm{~h}$. Leaves were blotted dry, transferred to a $2-\mathrm{mL}$ microcentrifuge tube, immediately frozen in liquid nitrogen, and then stored at $-80{ }^{\circ} \mathrm{C}$. Samples were ground with a micropestle and centrifuged at 20,817 $g_{n}$ (Eppendorf 5430 R; USA Scientific, Ocala, FL) for $15 \mathrm{~min}$ at room temperature. A $10-\mu \mathrm{L}$ leaf extract was placed on a piece of 0.5 -cm-diameter filter paper, inserted into a vapor pressure osmometer (5520 VAPRO; Wescor, Logan, UT) to obtain leaf solute molarity. The conversion from molarity to $\mathrm{MPa}$ was calculated as $\Psi_{\mathrm{s}}=-C \times R \times T$, where $C$ is the leaf solute molarity, $T$ the absolute temperature of $310 \mathrm{~K}$, and $R$ the constant $\left(8.314 \mathrm{~cm}^{3} \mathrm{MPa} \cdot \mathrm{K}^{-1} \cdot \mathrm{mol}^{-1}\right)$.

CTD is an indication of transpiration rate and has been widely used as a method to evaluate plant stress (Blum et al., 1982). Turf canopy temperatures were measured using an infrared thermometer (Davis Instruments, Vernon Hills, IL). The temperature depression was calculated by subtracting ambient temperature in the growth chamber from the plant canopy temperature.

Mineral nUtRient Determination. For both experiments, $1 \mathrm{~g}$ of grass leaf tissue was harvested, dried at $60{ }^{\circ} \mathrm{C}$ in an oven for $3 \mathrm{~d}$, and ground through a 1-mm screen within a stainless steel grinder (Wiley Mini-Mill Stainless Steel, 120V, 60 Hz; Thomas Scientific; Swedesboro, NJ) (Campbell and Plank, 1992). The same amount of ground leaf tissue was digested in $10 \mathrm{~mL}$ of $16 \mathrm{~N} \mathrm{HNO}_{3}$ for $30 \mathrm{~min}$ in a microwave, and the prepared sample volume was brought to $50 \mathrm{~mL}$ with deionized water before measurement (Jones, 2001). $\mathrm{Na}^{+}, \mathrm{K}^{+}$, and $\mathrm{Ca}^{2+}$ were measured using inductively coupled plasma mass spectrometer (ICP-MS) (Optima 3300 DV ICP-MS emission spectrophotometer; A \& L Great Lakes Laboratories, Fort Wayne, IN) at wavelengths of 589.592, 766.490, and $317.933 \mathrm{~nm}$, respectively. Final results were reported as milligrams per gram dry weight.

PA Extraction. The method of Liu et al. (2011a) and Oefner et al. (1992) was used with modification to quantify the accumulation of free PAs in creeping bentgrass for both experiments with four biological replications. Modifications were necessary to improve the yield of PAs from creeping bentgrass samples in our preliminary studies. The major modification included the use of 5\% formic acid (SigmaAldrich, St. Louis, MO) during PA extraction instead of perchloric acid. For PA extraction, a 250-mg sample of frozen leaf tissue was ground with liquid nitrogen to obtain a fine powder with a mortar and pestle. A $1-\mathrm{mL}$ aliquot of $5 \%$ formic acid (prepared with water) was added to the ground leaf powder, and they were ground further until a fine slurry was reached. The ground sample slurry was collected in a 2-mL microcentrifuge tube and stored in $\mathrm{a}-80^{\circ} \mathrm{C}$ freezer for further processing. To prepare the samples for derivatization, the samples were allowed to thaw at room temperature and were centrifuged for $30 \mathrm{~min}$ at $20,817 g_{\mathrm{n}}$ at $4{ }^{\circ} \mathrm{C}$. The supernatant containing PAs was transferred to a fresh, sterile $2-\mathrm{mL}$ microcentrifuge tube. The $\mathrm{pH}$ of the supernatant was adjusted to be higher than 12.0 with $2 \mathrm{~m} \mathrm{NaOH}$ (Fisher Scientific, Fair Lawn, NJ). The samples were then dried in a vacuum evaporator (79703-00 CentriVap; Labconco, KS City, MO) at room temperature. 
The dried samples were resuspended in $500 \mu \mathrm{L}$ of $4 \%$ benzoyl chloride (prepared in acetone; Sigma-Aldrich) and incubated at $30{ }^{\circ} \mathrm{C}$ for $2 \mathrm{~h}$, with shaking. After incubation, the supernatant was centrifuged $\left(20,817 g_{n}\right)$ and was mixed with $500 \mu \mathrm{L}$ of a saturated $\mathrm{NaCl}$ solution and $1 \mathrm{~mL}$ of dichloromethane (99\%; ACRO, Bridgewater, $\mathrm{NJ})$ in a $15-\mathrm{mL}$ centrifuge tube. Samples were centrifuged at $20,817 g_{\mathrm{n}}$ for $5 \mathrm{~min}$ at room temperature. After centrifugation, the bottom layer containing derivatized PAs was collected with a pipette. Benzoyl chloridederivatized PAs in dichloromethane (total $2 \mathrm{~mL}$ volume) were washed with an equal amount of water three times to get rid of salts by pipetting. Finally, samples were lyophilized in a freeze dryer (Genesis Pilot, Genesis 25L; SP Scientific, Warminster, $\mathrm{PA})$ at room temperature. Dried samples were resuspended in $60 \%$ methanol for high-performance liquid chromatography (HPLC) MS analysis.

External Standard Preparation. Put, Spd, and Spm (Sigma-Aldrich) stock solutions of $0.5 \mathrm{~mm} \cdot \mathrm{L}^{-1}$ were prepared in 5\% formic acid. Samples were evaporated to dryness at room temperature in a vacuum concentrator (Savant SPD111V; Thermo Fisher Scientific, Waltham, MA) and subjected to benzoyl chloride derivatization as described in PA Extraction section. Finally, standards were resuspended in $60 \%$ methanol to prepare a standard curve before loading onto the HPLC-MS in the same manner as the other analytes described below. The positive ions for detection of Put, Spd, and Spm were $\mathrm{m} / \mathrm{z}$ $319.1, \mathrm{~m} / \mathrm{z} 480.2$, and $\mathrm{m} / \mathrm{z} 641.3$, respectively. The reproducibility of the instrument was validated by injection of the mixtures of those three standards at a concentration of $30 \mu \mathrm{M} \cdot \mathrm{L}^{-1}$. A $60 \%$ methanol solvent was used as a blank between every six analytes to show that there was no carryover from the previous sample.

INSTRUMENTATION AND CHROMATOGRAPHIC CONDITIONS. Both experiments were performed at room temperature based on the method of Liu et al. (2011a) with modifications. Benzoyl chloride-derivatized PA samples were analyzed using HPLCMS (Quattro micro; Waters, Milford, MA) coupled with a binary pump (LC-20 AD) and auto-sampler (SIL 5000 Auto injector; Shimadzu, Columbia, MD). Derivatized PAs were injected into a C18 column $(5 \mathrm{~cm} \times 2.1 \mathrm{~mm} \times 2.7 \mu \mathrm{m}$; Ascentis Express, Sigma-Aldrich) at the gradient of $30 \%$ phase B and $70 \%$ phase A for the first $5 \mathrm{~min}, 74 \% \mathrm{~B}$ and $26 \% \mathrm{~A}$ for the next $10 \mathrm{~min} ; 30 \% \mathrm{~B}$ and $70 \% \mathrm{~A}$ started at $10.01 \mathrm{~min}$ and was kept for another $3 \mathrm{~min}$ to get column equilibrium with the flow rate of $0.3 \mathrm{~mL} \cdot \mathrm{min}^{-1}$. The mobile phases $\mathrm{A}$ and $\mathrm{B}$ were water and methanol, respectively. The electrospray ionization positive mode and single ion recording (SIR) data type were used to acquire PAs $\mathrm{Na}$ adduct ions. The source and dissolution temperature was set at 100 and $350{ }^{\circ} \mathrm{C}$, respectively. Capillary and cone voltage was $3.17 \mathrm{kV}$ and $35 \mathrm{~V}$, respectively. Dissolution gas flow was set at $600 \mathrm{~L} \cdot \mathrm{h}^{-1}$ and cone gas flow was $30 \mathrm{~L} \cdot \mathrm{h}^{-1}$.

EXPERIMENTAL DESIGN AND STATISTICAL ANALYSIS. Initially, all data of each trait were tested for their normality and homogeneity using the univariate procedure in SAS (version 9.4; SAS Institute, Cary, NC), and were normally distributed with uniform homogeneity. Therefore, all of the raw data were analyzed by using PROC MIXED based on the mixed linear model in SAS. Significant differences $(P \leq 0.05)$ of means for each trait at each time point were separated by using Fisher's least significant difference test in the LSMEANS procedure.

\section{Results}

Physiological traits evaluation. In both experiments, TQ declined due to salt stress whereas control plants did not decrease in TQ (Fig. 1). TQ decreased significantly after $\approx 42 \mathrm{~d}\left(16 \mathrm{dS} \cdot \mathrm{m}^{-1}\right)$ of salt treatment in Expt. 1 (Fig. 1A). However, in Expt. 2, the quality decreased in 'PsgSLTZ' later than in 'Penncross', which happened after $49 \mathrm{~d}\left(12 \mathrm{dS} \cdot \mathrm{m}^{-1}\right)$ of salt treatment (Fig. 1B). Major differences in TQ were detected when comparing cultivars under salt treatment on two dates ( 35 and 70 d) in Expt. 1 (Fig. 1A). EL remained consistently low at $\approx 12 \%$ for control plants in both experiments (Fig. 1C and D). In both experiments, EL levels began to significantly increase in salt-treated plants compared with controls of both cultivars at $42 \mathrm{~d}\left(16 \mathrm{dS} \cdot \mathrm{m}^{-1}\right)$ and $49 \mathrm{~d}$ $\left(12 \mathrm{dS} \cdot \mathrm{m}^{-1}\right)$ of salt treatment (Fig. $1 \mathrm{C}$ and D). The EL levels of 'PsgSLTZ' were generally higher than in 'Penncross' in the later stage of salt treatment in both experiments (Fig. 1C and D). The $\Psi_{\mathrm{s}}$ levels in both cultivars were maintained at $\approx-0.5 \mathrm{MPa}$ for control plants throughout the duration of both experiments (Fig. 2A and B). About $28 \mathrm{~d}$ after salt treatment, a significant decrease in $\Psi_{\mathrm{s}}$ was observed in salt-treated plants from both experiments (Fig. 2A and B). However, the amount of decrease in 'PsgSLTZ' was significantly less than in 'Penncross' on some sampling days in both experiments (Fig. 2A and B). No significant differences were detected for CTD between cultivars in both experiments under either control or salt-stressed conditions (Fig. 2C and D); however, control plants exhibited significantly lower CTD than the salt-stressed plants in both experiments (Fig. 2C and D).

Mineral nutrient content. Plant leaf $\mathrm{Na}^{+}$content increased significantly due to salt treatment in both cultivars of both experiments (Fig. 3). Under moderate salt stress conditions $(21 \mathrm{~d})$, both cultivars had similar $\mathrm{Na}^{+}$content accumulations in both experiments (Fig. 3A and B). After prolonged salt stress (70 d), 'PsgSLTZ' accumulated significantly less $\mathrm{Na}^{+}$ than 'Penncross' during both experiments (Fig. 3A and B). Plant leaf $\mathrm{Ca}^{2+}$ content decreased significantly compared with controls for both cultivars due to salt stress in both experiments (Fig. 3C and D). No significant differences were detected due to salt stress in $\mathrm{Ca}^{2+}$ content between the two cultivar types in the two experiments (Fig. 3C and D). Plant leaf $\mathrm{K}^{+}$content decreased significantly due to salt stress in both experiments (Fig. 3E and F). 'PsgSLTZ' had significantly higher $\mathrm{K}^{+}$content than 'Penncross' on 35 and $70 \mathrm{~d}$ of salt stress in Expt. 1 (Fig. 3E) and on days 49, 63, and 77 in Expt. 2 (Fig. 3F).

PA Content. Before optimizing the extraction, column size, solvent, and mobile phase described here, Spd and Spm were not resolved into separate peaks and therefore could not be quantified. The percent area after optimizing the method was 94\% for the three PAs standards. PA extraction in formic acid instead of perchloric acid proved to be a more effective method for extraction of PAs in HPLC-MS detection from creeping bentgrass tissues. The method was validated by making a standard calibration curve with all three standards from a fixed concentration of $0.1,1,2,5,10,25 \mu \mathrm{M} \cdot \mathrm{L}^{-1}$ and the linearity correlation coefficient $\left(r^{2}\right)$ based on the space between peak areas. The correlation coefficients for Put, Spd, and Spm were $0.983,0.984$, and 0.971 , respectively. Residual carryover in the instrument was not detected. This was confirmed by placing $60 \%$ of methanol between every six analytes, and the standard deviations for all the analytes ranged from $0.0 \%$ to $0.5 \%$. 


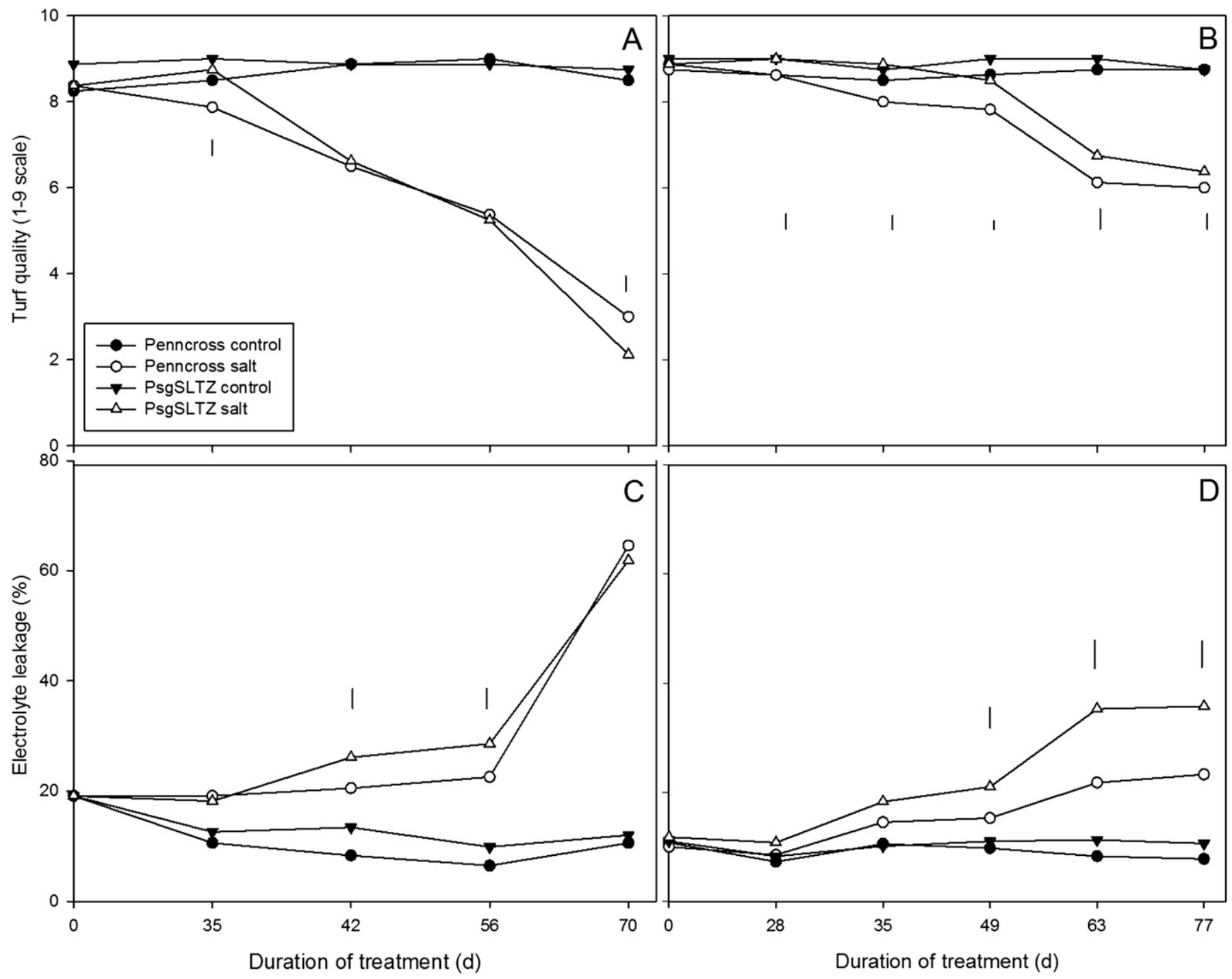

Fig. 1. Turf quality rating of creeping bentgrass 'PsgSLTZ' and 'Penncross' exposed to salt stress treatment in (A) Expt. 1, which was started on 21 Dec. 2013 , and (B) Expt. 2, which was started on 6 May 2014. Percent electrolyte leakage of leaves in (C) Expt. 1 and (D) Expt. 2. Treatment means were separated using Fisher's least significant difference $(\mathrm{n}=4)(P \leq 0.05)$, which is represented by the vertical bar. Rating was from $1=$ poor to $9=$ excellent based on turf color, uniformity, and density.

During these tests, no peaks were found at the designated retention time points.

Based on each linear curve of the PA standards, the range of quantities of the samples ranged from 263 to $5607 \mathrm{nmol} \cdot \mathrm{g}^{-1}$ FW. Salt stress caused an increase in Put production compared with control plants in both experiments (Fig. 4A and B); however, Put content induction in 'PsgSLTZ' was lower compared with 'Penncross' on 7 and $21 \mathrm{~d}$ after salt treatment in Expt. 1 (Fig. 4A). In Expt. 2, a similar trend occurred except for on $28 \mathrm{~d}$ after salt treatment in which 'PsgSLTZ' had a high Put content compared with 'Penncross' (Fig. 4B). The overall content of Spd production was greater in Expt. 1 (Fig. 4C) compared with Expt. 2 (Fig. 4D). Spd content in 'PsgSLTZ' was significantly higher compared with 'Penncross' in the early stage ( $21 \mathrm{~d}$ ) of salt stress in Expt. 1 (Fig. 4C). For the remaining time points measured for $\mathrm{Spd}$, no significant differences were detected in salt-treated plants compared with the control plants from both experiments (Fig. 4C and D). Spm production was generally induced by salt stress in both experiments (Fig. 4E and F). For Expt. 1, Spm content was significantly greater in salt-treated plants on 21 and $35 \mathrm{~d}$ (Fig. 4E). On these days, 'PsgSLTZ' had significantly greater Spm content than in 'Penncross' (Fig. 4E). Under prolonged salt stress conditions (70 d), Spm content was at or below the level of control plants (Fig. 4E). A similar trend was observed for Expt. 2 (Fig. 4F). On $49 \mathrm{~d}$ of treatment, 'PsgSLTZ' had a greater level of Spm content, whereas on $63 \mathrm{~d}$ of treatment 'Penncross' had significantly greater levels of Spm (Fig. 4F).

\section{Discussion}

The results of the physiological traits evaluated in this study indicate that both 'PsgSLTZ' and 'Penncross' creeping bentgrass experienced similar levels of damage due to salt treatments in both experiments. Salt exposure of these two creeping bentgrass cultivars resulted in an accumulation of $\mathrm{Na}^{+}$in plant 


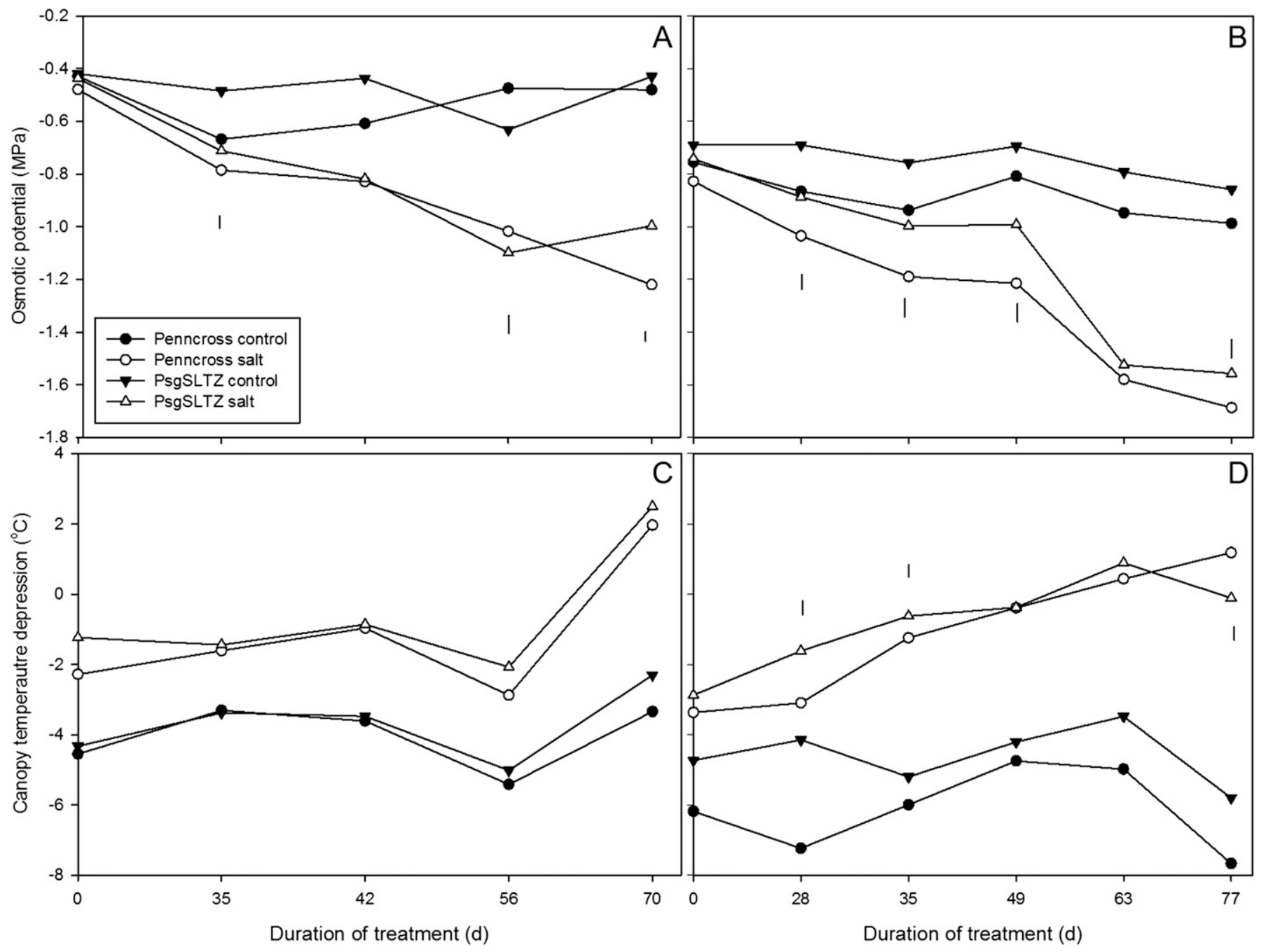

Fig. 2. Leaf osmotic potential of creeping bentgrass 'PsgSLTZ' and 'Penncross' exposed to salt stress treatment in (A) Expt. 1, which was started on 21 Dec. 2013, and (B) Expt. 2, which was started on 6 May 2014. Canopy temperature depression presented in (C) Expt. 1 and (D) Expt. 2. Treatment means were separated using Fisher's least significant difference at $P \leq 0.05(\mathrm{n}=4)$, which is represented by the vertical bar.

leaves and a reduction in $\mathrm{Ca}^{2+}$ and $\mathrm{K}^{+}$content in both experiments. 'PsgSLTZ' exhibited significantly higher $\mathrm{K}^{+}$ (throughout salt treatment), significantly lower $\mathrm{Na}^{+}$(on the last day of salt stress in both experiments), less change in $\Psi_{\mathrm{s}}$ (on most dates of both experiments) compared with 'Penncross'. This is relatively consistent with our previous studies of other creeping bentgrass cultivars differing in salt tolerance (Krishnan and Merewitz, 2015). Salt stress may reduce the content of $\mathrm{K}^{+}$and $\mathrm{Ca}^{2+}$ and maintenance of $\mathrm{K}^{+}$is associated with salt tolerance (Krishnan and Merewitz, 2015; Qian and Fu, 2005; Sairam et al., 2002). We cannot fully conclude whether the cultivars differed in salt tolerance from the results of this study, as more morphological and physiological data would be required. Further research and physiological characterization is needed to better understand potential salt tolerance attributes of various creeping bentgrass cultivars.

Creeping bentgrass does not readily exhibit salt escape or avoidance mechanisms (Marcum, 2001). Plants use salt tolerance mechanisms, such as accumulation of osmolytes, production of antioxidants, and other mechanisms to deal with salt accumulation (Fry and Huang, 2004). A tolerance mechanism to various abiotic stresses in creeping bentgrass is proposed to be the regulation of gene expression and biochemical pathways controlling PA content homeostasis. Common PAs (Put, Spd, and $\mathrm{Spm}$ ) are thought to act as regulatory molecules in plant cells by binding and modulating nucleic acids under abiotic stresses (Gill and Tuteja, 2010; Marco et al., 2011; Yang et al., 2007). Some research focuses on the function of conjugated PAs for protection in salt stressed tissues (Quinet et al., 2010; Yang et al., 2007); however, free PA is still the main form of this compound studied for its function under stress conditions. Free PA homeostasis depends on their synthesis, transport, degradation, and conjugation, which can be highly complex related to abiotic stress tolerance (Groppa and Benavides, 2008; Minocha et al., 2014). Whether PA content production may be a tolerance mechanism to abiotic stresses in turfgrass species has not yet been fully elucidated. Particularly, little information is available on the function, content, or regulation of these PAs in turfgrass species, such as high-value creeping bentgrass.

To quantify PAs in creeping bentgrass, current methods of PA quantification did not work well in our preliminary tests. The method described here is an economic and simple 

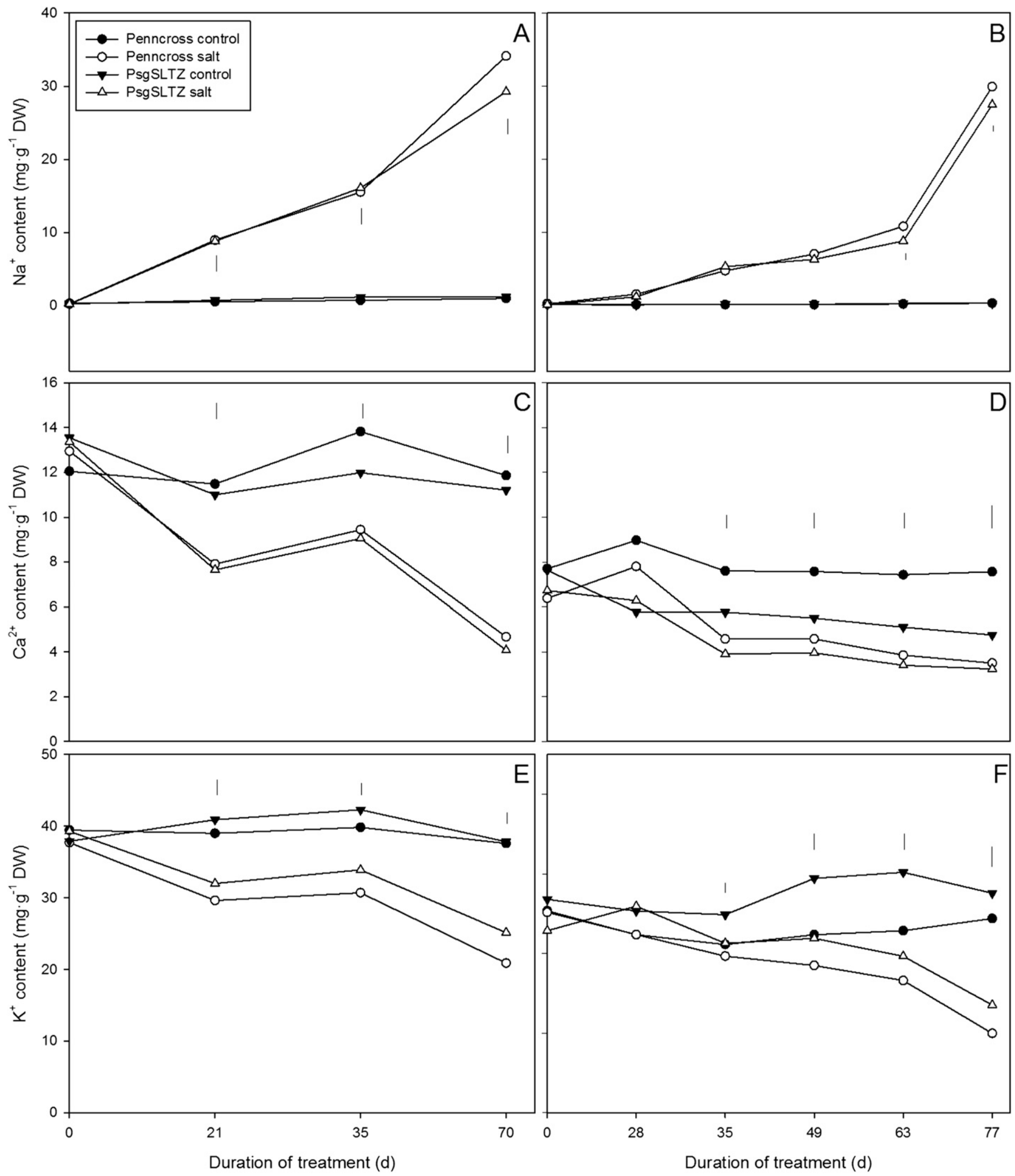

Fig. 3. Leaf mineral content of creeping bentgrass 'PsgSLTZ and 'Penncross' under salt stress. Leaf content of (A) $\mathrm{Na}^{+}(\mathbf{C}) \mathrm{Ca}^{2+}$, and (E) $\mathrm{K}^{+}$in 'PsgSLTZ' and 'Penncross' from Expt. 1 (B) $\mathrm{Na}^{+}$(D) $\mathrm{Ca}^{2+}$, and $(\mathbf{F}) \mathrm{K}^{+}$for Expt. 2. Treatment means were separated using Fisher's least significant difference at $P \leq 0.05$ ( $\mathrm{n}=4$ ), which is represented by the vertical bar. Day 0 for Expts. 1 and 2 started on 21 Dec. 2013 and 6 May 2014, respectively.

technique that is a method modified from Liu et al. (2011a) and Oefner et al. (1992). After optimizing the method, $5 \%$ formic acid was used to extract free PA from creeping bentgrass while
Liu and Moriguchi (2011) used $10 \% \mathrm{HClO}_{4}$ as extraction buffer from human urine. This modification is more accommodating for HPLC-MS equipment due to its higher volatility compared 

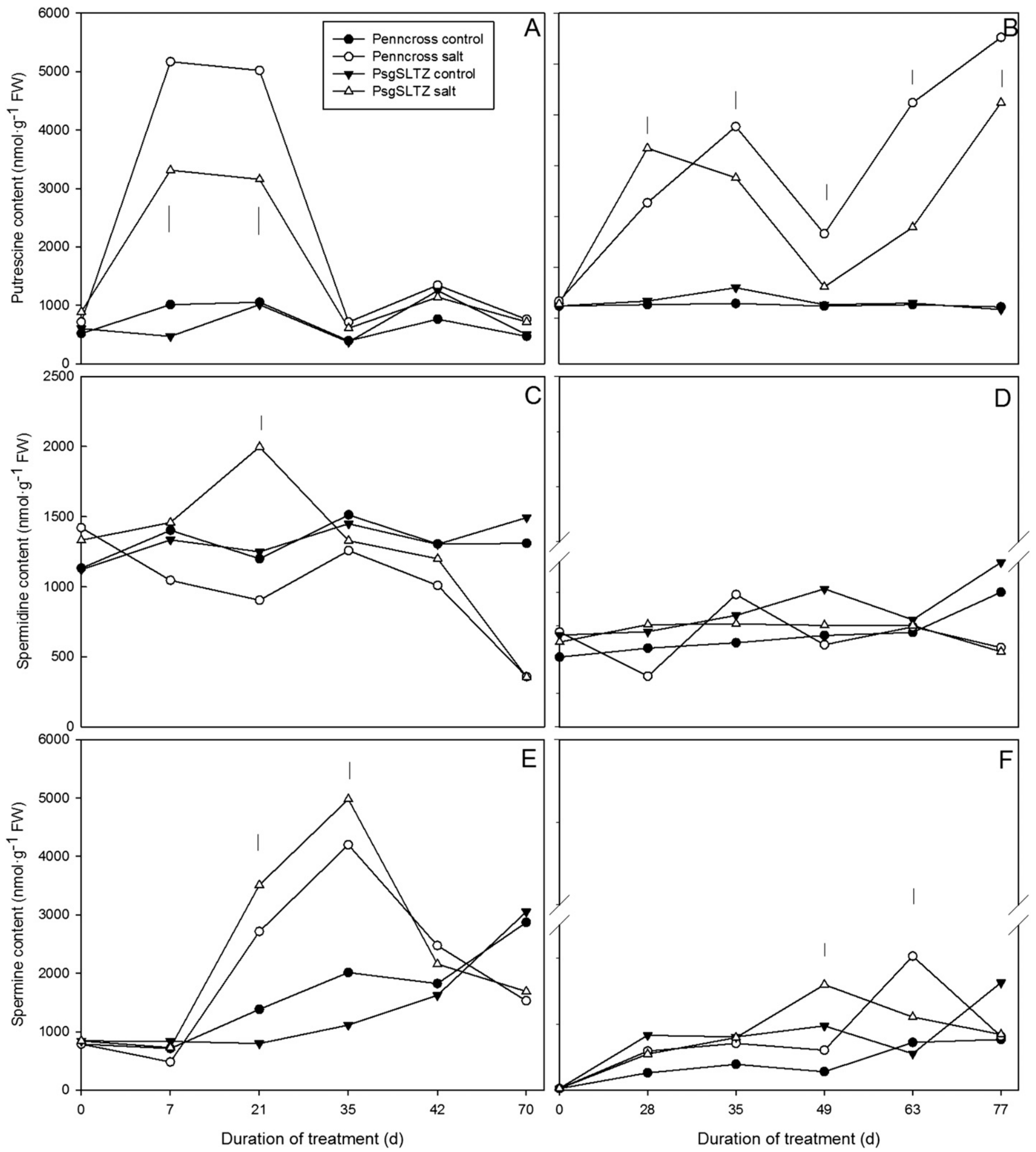

Fig. 4. Content of free polyamines in leaves of creeping bentgrass 'PsgSLTZ' and 'Penncross' under salt stress. Putrescine content in (A) Expt. 1 and (B) Expt. 2. Spermidine content in (C) Expt. 1 and (D) Expt. 2. Spermine content in (E) Expt. 1 and (F) Expt. 2. Treatment means were separated using Fisher's least significant difference at $P \leq 0.05(\mathrm{n}=4)$, which is represented by the vertical bar. Day 0 for Expts. 1 and 2 started on 21 Dec. 2013 and 6 May 2014 , respectively.

with perchloric acid. Using HPLC-MS through electro-spray ionization positive mode and single ion recording (SIR) data type, based on the mass-to-charge ratio of the compound, is different from what has been used in other experiments $(\mathrm{Li}$ et al., 2015a, 2015b). These experiments have used the method as described in the work of Duan et al. (2008), and it is based on ultraviolet detection within HPLC (Liu and Moriguchi, 2007). Compared with a ultraviolet detector, the MS detection 
technique in HPLC-MS is considered to be more precise and free of background interference (Holcapek et al., 2012; Mayr and Schieberle, 2012) because of the polarities of PAs [Put ${ }^{2+}$, $\mathrm{Spd}^{3+}$, and $\mathrm{Spm}^{4+}$ (Vafaeezadeh et al., 2016)]. Furthermore, the retention time (24 min) that Liu et al. (2011a) used in liquid chromatography quadruple time-of-flight MS was longer while our HPLC-MS used only $13 \mathrm{~min}$ for PA detection without carryover, which is more economical by saving analytic time. Besides, the mobile phase program for their method was 55\% A (water) from 0 to $14 \mathrm{~min}$ and $74 \% \mathrm{~A}$ from 14 to $24 \mathrm{~min}$, which was different from ours (see Material and Method section). Our mobile phase program is optimized to be beneficial for the mass analyzer to separate and detect PA ions. The flow rate, which affects the sensitivity of mass detector, in this method $\left(0.3 \mathrm{~mL} \cdot \mathrm{min}^{-1}\right)$ was different from that of Liu et al. (2011a) $\left(1 \mathrm{~mL} \cdot \mathrm{min}^{-1}\right)$. Also, the smaller column size compared with that of Liu et al. (2011a) is better for a higher peak resolution. It is necessary to optimize the method as technologies become more advanced. To our knowledge, only one other published study has evaluated PAs from creeping bentgrass ('Penn-A4') leaf tissue. Their study aimed to evaluate PA content after treatment with exogenously applied PAs in response to drought stress $(\mathrm{Li}$ et al., 2015b). The method described here allowed for detection of $\approx 100$ times the level of PAs in response to salinity stress ( $\mathrm{Li}$ et al., 2015b); however, it is worthy to note that this difference could also be related to differences in the cultivar used and experimental conditions.

In this study, we have found that the monocot, creeping bentgrass, may exhibit PA regulation in response to salt stress. An increase in Put, no significant changes in Spd and an increase in Spm were observed due to salt stress of both creeping bentgrass cultivars (Fig. 4). Similarly, in grape (Vitis vinifera) seedlings, Put and Spm content and PA biosynthesis gene expression was induced when grown in media with $200 \mathrm{~mm} \mathrm{NaCl}$ (Liu et al., 2011b). Creeping bentgrass 'PsgSLTZ' overall exhibited less production of Put and higher production of Spm in response to salt stress (Fig. 4A and E), which could be associated with a greater salt tolerance. Zapata et al. (2004) studied free PA accumulation in seven crop species including spinach (Spinacia oleracea), lettuce (Lactuca sativa), tomato (Solanum lycopersicum), melon (Cucumis melo), pepper (Capsicum annuum), broccoli (Brassica oleraceae var. italica), and beetroot (Beta vulgaris) under salinity stress. Slightly alternate results were observed in their study since, in most of these dicot species under salt stress, a decrease in Put and an increase in Spd and Spm was observed. They attributed a higher amount of Spd and Spm with a low amount of Put to be associated with salt tolerance. A similar trend was also found in seedlings of common wheat (Triticum aestivum), since Put decreased under saline stress while a significant increase in Spd and Spm occurred (Capell et al., 2004; El-Shintinawy, 2000; Maiale et al., 2004). However, the results found here were mostly consistent with a salt stress study in the monocot grass species rice, in which salt sensitivity of a rice cultivar was associated with accumulation of Put and low level of Spd and Spm (Krishnamurthy and Bhagwat, 1989). Creeping bentgrass 'PsgSLTZ' overall exhibited less production of Put in response to salt stress, which could be associated with a greater salt tolerance; however, based on physiological evaluation, the cultivar differences in salt tolerance were not fully clear. Thus, it seems that these two creeping bentgrass cultivars exhibit a trend in PA content changes that are associated with salt sensitivity. Therefore, supplementation of PA biochemical pathways via exogenous application of PAs or by genetic modification may be beneficial for creeping bentgrass survival of salt stress.

In conclusion, both creeping bentgrass cultivars exhibited a significant decline in plant health due to salt treatment. PA content was also affected by salt stress treatment. Overall, Put increased due to salt stress while Spd was generally unaffected and Spm had a transient increase in content due to salt stress. Since creeping bentgrass exhibits PA regulation that may be associated with stress sensitivity, the enhancement of PA regulation in creeping bentgrass, such as through exogenous application or molecular techniques, may be a viable method of improving creeping bentgrass tolerance to salt. In our recent work, we have found that exogenous application of PAs did improve creeping bentgrass responses to drought stress (Shukla et al., 2015). More work is needed to elucidate the physiological effects of PAs in relation to abiotic stresses in turfgrass species.

\section{Literature Cited}

Alcazar, R., M. Bitrian, D. Bartels, C. Koncz, T. Altabella, and A.F. Tiburcio. 2011. Polyamine metabolic canalization in response to drought stress in arabidopsis and the resurrection plant Craterostigma plantagineum. Plant Signal. Behav. 6:243-250.

Beard, J.B. 2001. Turf management for golf courses. 2nd ed. Ann Arbor Press, Chelsea, MI.

Blum, A. and A. Ebercon. 1981. Cell membrane stability as a measure of drought and heat tolerance in wheat. Crop Sci. 21:43-47.

Blum, A., J. Mayer, and G. Gozlan. 1982. Infrared thermal sensing of plant canopies as a screening technique for dehydration avoidance in wheat. Field Crops Res. 5:137-146.

Campbell, C.R. and C.O. Plank. 1992. Sample preparation. In: C.O. Plank (ed.). Plant analysis reference procedures for the southern region of the United States. Southern Coop. Ser. Bul. 368:1-11.

Capell, T., L. Bassie, and P. Christou. 2004. Modulation of the polyamine biosynthetic pathway in transgenic rice confers tolerance to drought stress. Proc. Natl. Acad. Sci. USA 101:9909-9914.

Do, P.T., O. Drechsel, A.G. Heyer, D.K. Hincha, and E. Zuther. 2014. Changes in free polyamine levels, expression of polyamine biosynthesis genes, and performance of rice cultivars under salt stress: A comparison with responses to drought. Front. Plant Sci. 5:1-16.

Duan, J., J. Li, S. Guo, and Y. Kang. 2008. Exogenous spermidine affects polyamine metabolism in salinity-stressed Cucumis sativus roots and enhances short-term salinity tolerance. J. Plant Physiol. 165:1620-1635.

Duncan, R.R., R.N. Carrow, and M.T. Huck. 2008. Turfgrass and landscape irrigation water quality: Assessment and management. CRC Press, Boca Raton, FL.

El-Shintinawy, F. 2000. Photosynthesis in two wheat cultivars differing in salt susceptibility. Photosynthetica 38:615-620.

Fry, J. and B. Huang. 2004. Applied turfgrass science and physiology. Wiley, Somerset, NJ.

Gill, S.S. and N. Tuteja. 2010. Polyamines and abiotic stress tolerance in plants. Plant Signal. Behav. 5:26-33.

Groppa, M.D. and M.P. Benavides. 2008. Polyamines and abiotic stress: Recent advances. Amino Acids 34:35-45.

Hasegawa, P.M., R.A. Bressan, J.K. Zhu, and H.J. Bohnert. 2000. Plant cellular and molecular responses to high salinity. Annu. Rev. Plant Physiol. Plant Mol. Biol. 51:463-499.

Hoagland, D.R. and D.I. Arnon. 1950. The water-culture method for growing plants without soil. 2nd ed. California Agr. Expt. Sta. Circ. 347. Holcapek, M., R. Jirásko, and M. Lísa. 2012. Recent developments in liquid chromatography-mass spectrometry and related techniques. J. Chromatography 1259:3-15. 
Janowitz, T., H. Kneifel, and M. Piotrowski. 2003. Identification and characterization of plant agmatine iminohydrolase, the last missing link in polyamine biosynthesis of plants. FEBS Lett. 544:258-261.

Jones, J.B. 2001. Laboratory guide for conducting soil tests and plant analysis. CRC Press, Boca Raton, FL.

Krishnamurthy, R. and K.A. Bhagwat. 1989. Polyamines as modulators of salt tolerance in rice cultivars. Plant Physiol. 91:500-504.

Krishnan, S.K. and E. Merewitz. 2015. Phytohormone responses and cell viability during salinity stress in two creeping bentgrass cultivars differing in salt tolerance. J. Amer. Soc. Hort. Sci. 140:346-355.

Li, Z., Y. Zhang, D. Peng, X. Wang, Y. Peng, X. He, X. Zhang, X. Ma, L. Huang, and Y. Yan. 2015a. Polyamine regulates tolerance to water stress in leaves of white clover associated with antioxidant defense and dehydrin genes via involvement in calcium messenger system and hydrogen peroxide signaling. Front. Physiol. 6:280-296.

Li, Z., H. Zhou, Y. Peng, X. Zhang, X. Ma, L. Huang, and Y. Yan. 2015b. Exogenously applied spermidine improves drought tolerance in creeping bentgrass associated with changes in antioxidant defense, endogenous polyamines and phytohormones. Plant Growth Regulat. 76:71-82.

Liu, R., Y. Jia, W. Cheng, J. Ling, L. Liu, K. Bi, and Q. Li. 2011 a. Determination of polyamines in human urine by precolumn derivatization with benzoyl chloride and high-performance liquid chromatography coupled with Q-time-of-flight mass spectrometry. Talanta 83:751-756.

Liu, J.H. and T. Moriguchi. 2007. Changes in free polyamine titers and expression of polyamine biosynthetic genes during growth of peach in vitro callus. Plant Cell Rpt. 26:125-131.

Liu, J.H., I. Nakajima, and T. Moriguchi. 2011b. Effects of salt and osmotic stresses on free polyamine content and expression of polyamine biosynthetic genes in Vitis vinifera. Biol. Plant. 55:340 344.

Maiale, S., D.H. Sánchez, A. Guirado, A. Vidal, and O.A. Ruiz. 2004. Spermine accumulation under salt stress. J. Plant Physiol. 161:35-42. Marco, F., R. Alcazar, A.F. Tiburcio, and P. Carrasco. 2011. Interactions between polyamines and abiotic stress pathway responses unraveled by transcriptome analysis of polyamine overproducers. OMICS. 15:775-781.

Marcum, K.B. 2001. Salinity tolerance of 35 bentgrass cultivars. HortScience 36:374-376.

Mayr, C.M. and P. Schieberle. 2012. Development of stable isotope dilution assays for the simultaneous quantitation of biogenic amines and polyamines in foods by LC-MS/MS. J. Agr. Food Chem. 60:3026-3032.
Minocha, R., R. Majumdar, and S.C. Minocha. 2014. Polyamines and abiotic stress in plants: A complex relationship. Front. Plant Sci. $5: 175-182$.

Oefner, P.J., S. Wongyai, and G. Bonn. 1992. High-performance liquid chromatographic determination of free polyamines in human seminal plasma. Clin. Chim. Acta 205:11-18.

Qian, Y. and J.D. Fry. 1997. Water relations and drought tolerance of four turfgrasses. J. Amer. Soc. Hort. Sci. 122:129-133.

Qian, Y.L. and J.M. Fu. 2005. Response of creeping bentgrass to salinity and mowing management: Carbohydrate availability and ion accumulation. HortScience 40:2170-2174.

Quinet, M., A. Ndayiragije, I. Lefevre, B. Lambillotte, C.C. DupontGillain, and S. Lutts. 2010. Putrescine differently influences the effect of salt stress on polyamine metabolism and ethylene synthesis in rice cultivars differing in salt resistance. J. Expt. Bot. 61:2719-2733.

Rodriguez, A.A., S.J. Maiale, A.B. Menendez, and O.A. Ruiz. 2009. Polyamine oxidase activity contributes to sustain maize leaf elongation under saline stress. J. Expt. Bot. 60:4249-4262.

Sadak, M.S. and M.T. Abdelhamid. 2015. Influence of amino acids mixture application on some biochemical aspects, antioxidant enzymes and endogenous polyamines of Vicia faba plant grown under seawater salinity stress. Gesunde Pflanzen 67:119-129.

Sairam, R.K., K.R. Veerabhadra, and G.C. Srivastava. 2002. Differential response of wheat genotypes to long term salinity stress in relation to oxidative stress, antioxidant activity and osmolyte concentration. Plant Sci. 163:10371046.

Shukla, V., Y. Ma, and E. Merewitz. 2015. Creeping bentgrass responses to drought stress and polyamine application. J. Amer. Soc. Hort. Sci. 140:94-101.

Sudhakar, C., G. Veeranagamallaiah, A. Nareshkumar, O. Sudhakarbabu, M. Sivakumar, M. Pandurangaiah, K. Kiranmai, and U. Lokesh. 2015. Polyamine metabolism influences antioxidant defense mechanism in foxtail millet (Setaria italica L.) cultivars with different salinity tolerance. Plant Cell Rpt. 34:141-156.

Vafaeezadeh, M., M.M. Hashemi, and N. Ghavidel. 2016. Polarity adjustment of a nanosilica-functionalized polyamine modified by ionic liquid for removal of $\mathrm{Cu}^{2+}$ from aqueous solutions. RSC Advances 6:14128-14134.

Yang, J., J. Zhang, K. Liu, Z. Wang, and L. Liu. 2007. Involvement of polyamines in the drought resistance of rice. J. Expt. Bot. 58:15451555.

Zapata, P.J., M. Serrano, M.T. Pretel, A. Amoros, and M.A. Botella. 2004. Polyamines and ethylene changes during germination of different plant species under salinity. Plant Sci. 167:781-788. 